www.jmscr.igmpublication.org

Impact Factor 5.84

Index Copernicus Value: 83.27

ISSN (e)-2347-176x ISSN (p) 2455-0450

crossref DOI: https://dx.doi.org/10.18535/jmscr/v5i1.133

Journal Of Medical Science And Clinical Research

IGM Publication

An Official Publication of IGM Publication

\title{
ABO Incompatibility and Neonatal Outcome with Reference to Hemolytic Disease of Newborn
}

\author{
Authors \\ Dr Shilpa Nair ${ }^{1}$, Dr Lakshmi B $S^{2}$ \\ ${ }^{1,2}$ Assistant Professor, Government Medical College Trivandrum
}

\begin{abstract}
Among the conditions capable of causing hemolytic disease of newborn, blood group incompatibility is the most common cause of which most severe forms are encountered in Rh incompatibility. However with availability of effective antenatal care in detecting Rh negative mothers and successful administration of Rh immunoglobulin ABO incompatibility has emerged the most common cause of haemolytic disease of newborn Objective

1. To determine the incidence of $A B O$ incompatibility and the incidence of neonatal jaundice in $A B O$ incompatibility

2. To determine the risk factors for development of neonatal jaundice in $A B O$ incompatibility

3. To determine the perinatal outcome of $A B O$ incompatible babies

Material and Methods: A prospective case control study conducted in the department of Obstetrics and Gynaecology, SAT hospital, government medical college Trivandrum. All O positive mothers delivered during the period were included in the study. Among the ABO incompatible babies, the development of jaundice was taken as the outcome and those babies who did not develop jaundice were taken as control. Risk factors for the development of jaundice in ABO incompatibility were assessed Statistical analysis was performed using chi square test

Results: A total of 250 O positive mothers were included in the study. Out of this 102(40.8\%) babies had ABO incompatibility, out of this $36 \%$ babies had jaundice. Jaundice due to ABO incompatibility was more in preterm babies and babies of those mothers who were given oxytocin augmentation. Among the jaundiced babies $27 \%$ underwent exchange transfusion

Conclusion: $A B O$ haemolytic disease of the newborn is characterised by a benign evolution because of a mild degree of hemolysis. Anemia is rare, the main clinical problem being jaundice. Severe haemolysis and anemia requiring exchange transfusion was reported in $27 \%$ only.

Keywords: $A B O$ incompatibility, jaundice, prematurity.
\end{abstract}

\section{Introduction}

ABO hemolytic disease of the newborn occurs almost exclusively in infants having blood group $\mathrm{A}$ or $\mathrm{B}$ who are born to $\mathrm{O}$ positive mothers. Although ABO incompatibility is common, haemolytic disease due to this has been reported to be low. Unlike the rhesus disease, it is usually a problem of the neonate rather than the fetus ABO haemolytic disease of newborn is caused by immune IgG maternal antibodies which have the ability to cross the placental barrier A high titre of these immune antibodies may not present with 
adverse effects in utero as $\mathrm{A}$ and $\mathrm{B}$ antigen are present in cells of all other tissues and body fluids and not only in red blood cells. The presence of these antigens help to protect the incompatible fetal red cells by neutralizing the transferred maternal antibody with small amount of antibody reacting directly with the fetal red blood cells ${ }^{[1]}$. The sensitized red cells are destroyed in the fetal spleen with consequent hyperbilirubinemia

The factors that hindered the general appreciation of $\mathrm{ABO}$ haemolytic disease according to Rosen field could generally be that $\mathrm{Rh}$ disease is readily recognizable with aid of direct anti globulin test whereas $\mathrm{ABO}$ disease may not be recognized easily ${ }^{[2]}$. Jaundice usually becomes evident in the first 24 hours of life. If it appears beyond 24 hours other causes of jaundice like sepsis, inherited red cell disorders and metabolic factors have to be considered. Neonatal jaundice occurs in $60 \%$ of term and $80 \%$ preterm infants ${ }^{[3]}$. Newborns incompatible with their mothers in the $\mathrm{ABO}$ system presents with potentially higher risk of severe hyperbilirubinemia especially in the presence of a positive direct coombs test ${ }^{[4]}$

The objective of this study is to assess the extent to which $\mathrm{ABO}$ incompatibility is implicated in neonatal jaundice in our population.

\section{Materials and Methods}

This prospective case control study was conducted in the department of Obstetrics and Gynaecology, SAT hospital government medical college Trivandrum over a period of 4 months A total of $250 \mathrm{O}$ positive mothers were included in the study. Detailed history of patient, previous obstetric history, antenatal complications in present pregnancy and details of the neonate were recorded. Cord blood of all mothers were sent for blood grouping, Rh typing and serum bilirubin. ABO incompatibile babies were followed up daily for the development of jaundice which was taken as the end point. Statistical significance of risk factors were analyzed using chi square test. Deteriorating cases were followed up for further management which included sun exposure, phototherapy, or exchange transfusion.

\section{Results}

Among the $250 \mathrm{O}$ positive mothers included in the study, 102 babies $(40.8 \%)$ ha $\mathrm{ABO}$ incompatibility. Clinical jaundice among ABO incompatibility was $36 \%$ (37 cases).

Table 1: Time of appearance of jaundice

\begin{tabular}{|l|c|c|}
\hline Time in hours & Number & Percentage \\
\hline$<24$ & 22 & 59 \\
\hline $24-48$ & 10 & 27 \\
\hline$>48$ & 5 & 14 \\
\hline Total & 37 & 100 \\
\hline
\end{tabular}

$59 \%$ of babies developed jaundice within 24 hours. Parity of mothers showed no statistical significance among the jaundiced and nonjaundiced in $\mathrm{ABO}$ incompatible babies.

Table 2: Distribution of gestational age of babies among jaundiced anf non-jaundiced in $\mathrm{ABO}$ incompatibles.

\begin{tabular}{|l|c|c|c|c|}
\hline \multirow{2}{*}{$\begin{array}{c}\text { Gestational } \\
\text { age in days }\end{array}$} & \multicolumn{2}{|c|}{ Jaundiced } & \multicolumn{2}{c|}{ Non -jaundiced } \\
\cline { 2 - 5 } & Number & $\%$ & Number & $\%$ \\
\hline$<260$ & 4 & 11 & & \\
\hline $260-280$ & 33 & 89 & 56 & 86 \\
\hline$>280$ & & & 9 & 14 \\
\hline
\end{tabular}

Out of 102 ABO incompatible pregnancies, $11 \%$ were preterm and all of them were jaundiced.

Table 3: Distribution of pregnant women with jaundiced and non-jaundiced babies with respect to oxytocin augmentation.

\begin{tabular}{|l|l|l|l|l|}
\hline \multirow{2}{*}{ Augmentation } & Jaundiced & \multicolumn{2}{l|}{ Non -jaundiced } \\
\cline { 2 - 5 } & Number & $\%$ & Number & $\%$ \\
\hline Oxytocin & 25 & 68 & 33 & 51 \\
\hline ARM & 5 & 13 & 6 & 9 \\
\hline No augmentation & 3 & 8 & 15 & 23 \\
\hline
\end{tabular}

$66 \%$ of women received oxytocin in the jaundiced group.

Among the $\mathrm{ABO}$ incompatible babies $46 \%$ were A positive and $54 \%$ were $\mathrm{B}$ positive. $32 \%$ of $\mathrm{ABO}$ incompatible babies had a cord bilirubin 3.2 and above. 
TABLE 4: Distribution of cord bilirubin in babies among jaundiced and non-jaundiced group.

\begin{tabular}{|l|c|c|c|c|}
\hline \multirow{2}{*}{ Cord Bilirubin } & \multicolumn{2}{|c|}{ Jaundiced } & \multicolumn{2}{c|}{ Non -jaundiced } \\
\cline { 2 - 5 } & Number & $\%$ & Number & $\%$ \\
\hline $0.2-1.2$ & 7 & 19 & 43 & 66 \\
\hline $1.2-2.2$ & 4 & 11 & 14 & 22 \\
\hline $2.2-3.2$ & 14 & 38 & 8 & 12 \\
\hline 3.2 and above & 12 & 32 & & \\
\hline Total & 37 & 100 & 65 & 100 \\
\hline
\end{tabular}

Phototherapy was the mainstay of treatment in $54 \%$ f cases and 27\% (10) cases required exchange transfusion.

\section{Discussion}

Among the $\mathrm{O}$ positive mothers included in the study, $40.8 \%$ had ABO incompatibility. Incidence reported in various studies range from $15 \%$ to $25 \%$. Some studies suggest ethnic difference with increased severity among Blacks ${ }^{[5]}$. Among the 102 incompatible babies, $36 \%$ were jaundiced. Similar reports were given by Dufour et al ${ }^{[6]}$.

The time of appearance of jaundice showed that $50 \%$ of jaundiced babies develop jaundice within 24 hours of delivery. In our series, incidence was high in preterm neonates. Similar finding was reported by Cashore et al ${ }^{[7]}$. This occurs due to the fact that preterm infants liver is unable to process bilirubin as well as a term infant and also the level of albumin is lower compared to term infant.

In our series, 43 male and 31 female neonates were in the jaundiced group and this was not statistically significant. Higher incidence among femaleshave been reported in some studies ${ }^{[8]}$. Various other studies have failed to demonstrate any correlation between sex of the babies and development of haemolytic disease of newborn ${ }^{[9]}$. Oxytocin augmentation was found to increase the development of jaundice probably due to increased osmotic fragility and water retention, similar to that reported in the literature. The maximum number of babies were in the 2.5 to $2.9 \mathrm{~kg}$ group in both jaundiced and non-jaundiced group. Mean difference in weight was not found to influence the development of jaundice. This is in agreement with reports by Kitchen $\mathrm{W} \mathrm{H}^{[10]}$. The mean cord bilirubin was found to be significantly higher in babies that developed jaundice as was reported by Risemberg ${ }^{[11]}$. $54 \%$ of jaundiced babies required phototherapy, $27 \%$ had exchange transfusion, $19 \%$ needed no treatment.

Routine screening for $\mathrm{ABO}$ incompatibility is not presently performed in our centre. There is no test that is of high predictive value for severe haemolytic disease.

\section{Conclusion}

Newborn incompatible with their mothers in the $\mathrm{ABO}$ system presents potentially high risk of neonatal hyperbilirubinemia. Incidence of jaundice was found to be more among premature babies. The neonate presents with jaundice, and anemia is usually rare. But there are cases which need exchange transfusion. Early detection and treatment of neonatal hyperblirubinemia is important in prevention of bilirubin induced encephalopathy in affected children.

\section{Reference}

1. Ottenberg R. Studies in isoagglutination: Transfusion and the question of intravascular agglutination. The Journal of Experimental Medicine 1911; 13: 425-438.

2. Rosenfield R E. A-B haemolytic disease of newborn. Analysis of 1480 cord blood specimen with special reference to the direct antiglobulin test and to the group $\mathrm{O}$ mother. Blood. 1955; 10: 17-28.

3. Stoll B J, Kliegman R M. Blood disorders. In Behrman R E, Kliegman R M, Jenson H B eds. Nelson's textbook of paediatrics. $16^{\text {th }}$ edition Philadelphia: WB Saunders Company, 2000; 525-526.

4. Orzalesi M, Gloria F, Lucarelli P, Bottini E. ABO system incompatibility: Relationship between direct Coombs test positivity and neonatal jaundice. Paediatrics 1973; 51: 288- 289. 
5. Kirkman H N. Further evidence of racial difference in frequency of $\mathrm{ABO}$ haemolytic disease. J Paediatrics 1977; 90: 717-719.

6. Dufour D R, Monaghan W P. ABO haemolytic disease of newborn. Am J Clin Path 1980; 73: 369-376.

7. Cashore W J, Horwich A, Karotkin et al. Influence of gestational age and clinical status on bilirubin binding capacity in newborn infants. Sephader $25 \mathrm{G}-25$ jel filtration technique. Am J Dis Child 1977; 131: 898-901.

8. Singh M. Jaundice. In Singh M eds. Care of newborn : $5^{\text {th }}$ edition New Delhi: Sagar publication , 1999: 249-252.

9. Sarici U S, Yurdakok M, Muhittin A et al. An early (sixth hour) Serum bilirubin measurement is useful in predicting the development of significant hyperbilirubinemia and severe ABO haemolytic disease in a selective high risk population of newborn with ABO incompatibility. Paediatrics 2002; 4: 109-112.

10. Kitchen WH. Birthweight of infants with Rhesus incompatibility. Aust NZ J Obstet Gynecol 1970; 10: 30-35.

11. Risemberg H M, Mazzi E, Mac Donald MG et al. Correlation of cord bilirubin with hyperbilirubinemia in ABO incomepatibility. Arch Dis Child 1977; 52: 219222. 